\title{
Racial Ideology Development in Children: A Cause, Implication and Strategy Study
}

\author{
Jianing Wang, ${ }^{1, *}$ \\ ${ }^{1}$ Ivey Business School, Western University, 1151 Richmond St, London, ON, Canada \\ ${ }^{*}$ Corresponding author.Email: Guanghua.ren@gecacdemy.cn
}

\begin{abstract}
This paper examines whether children can materialize racial ideologies. The central idea in this discussion is on racial ideologies and the aim is to find out whether children can possess racial ideologies. There is particularly more focus on the ages when the children are likely to develop the racial ideologies and the first behavioral features that can be observed. Ideally, racial ideology is not a popular thing because of the natural perception that kids are not able to categorize people according to race. However, children as young as six months can notice racial differences and have the propensity to react to that difference. Children are not colorblind and they can observe the people around them and categorize them accordingly. Hence, racial ideologies in children can start from as early as six months and is shaped by both the environment and the people the child interacts with henceforth.
\end{abstract}

Keywords: Racial ideology, Children, Racial identity.

\section{INTRODUCTION}

The daily interactions among individuals, family and groups are both socio-culturally and historically relevant in interpreting the development of racial ideology. According to Katz and Kofkin [1], parental racial socialization is commonly connected to racial identity where growing children begin to show awareness of racial categories. Racial awareness influences many things in children, including their attitudes and socialization. Racial identity means having specific attitudes, perceptions and beliefs towards one racial group compared to the bigger racial group. Having a racial ideology thus means possessing sentiments and facts related to specific racial groups and being conscious of the consequences or privileges of being part of a racial group. Racial ideologies have a significant impact on the way people relate and communicate. Racial ideologies are one of the profound reasons racism is a problem anchored deep in society and challenging to address. This paper will focus on how racial ideologies are established in childhood and shaped through established social structures. There is also a focus on parental socialization, which is a significant source of racial ideologies among children.

\section{RACIAL IDEOLOGY IN CHILDREN}

Racial ideology is common among children, which indicates that racial ideologies begin from childhood. The best way to understand how racial ideologies are shaped, several writers have conducted extensive research on racial and ethnic identity to find out how people become accustomed to various racial standpoints. Racial identity means how people define themselves in relation to their racial affiliation. Race, on the other hand, is best defined as a social construct that divides people in terms of physical appearance and origin. The term race has no biological association, much as so many people tend to feel that race has to do with biological aspects of a person. As used in various social contexts, many scholars agree that race is a social fabrication intended to categorize people mostly based on skin colour. There are no reliable studies to ascertain any genetic connection of race. There is also no reliable scientific research enough to justify race as something other than a social construction. According to the American anthropological association, individuals invented race whose intentions were perpetual to low accord status to people of certain origin [1]. Hence, the term racial identity has two bearings. The first meaning is externally imposed, which means people are curious about how others perceive them. The other meaning is an internal construction where individuals identify 
themselves with respect to race. Both definitions are crucial in understanding how racial ideologies are shaped among young children and the implications of having certain ideologies

\section{ROGRRESSIVE MODELS OF RACIAL IDENTITY}

Both psychologists and sociologists believe that there is an established trend through which individuals recognize their racial identity. Such a pattern is very particular with children who are constantly learning new things. Analyzing these patterns is very helpful in understanding the similarity between race and identity. The process of racial identity is different from one individual to another and from one group to another, but either way, there is a specific pattern in which racial identity is established. Children are easily influenced by their family, community and social events to become racially conscious. Hence, they become racially conscious at very early stages in their life. The sociologists rely on models such as "no one is colourblind to race" to explain why even children gain racial identity at very early stages of their lives. Based on this model, people will naturally notice physical differences such as skin colour. Even when the socialization around these people has nothing to do with racial disparities, detecting physical variations is one of the earliest signs even among children who understand racial identities. According to Aboud [2], children are not colour-blind to race, and they learn very fast any physical differences among themselves, which makes them racially aware, based on the variations. The children are also quick to observe the various social structures and how they are responsible for handling people based on race. Children will notice any minor disparity in the treatment of people based on their racial affiliation according to Winkler [3].

Winkler [3]states that children are blank slates who cannot have racial prejudice unless taught. Due to such a reason, many people believe that it is not okay to expose children to racial matters even in the course of teaching. But this does not mean that the children are not aware of the racial issues surrounding them. According to Winkler [3], children recognized race in their very tender ages and even express racial bias from the ages of 3 to 5, although such biases may not resemble attitudes of adults around them. The children have unique learning capabilities that cannot be underestimated. Kofkin [1] found in a research that comprised 200 young black and white children that children could categorize people by race and gender at the age of six months. The observation of his study was that a child could stare at the longer unfamiliar face of a different race and even posed unusual facial expressions. The study also found out that the child was less curious and posed a much more relaxed facial expression in the face of an unfamiliar person of the same race. The study concluded that such behaviour was very common with six-month-old infants, indicating that racial awareness begins at this age or even earlier.

Toddlers from as early as two years categorize people by race based on behaviour according to Cristol and Gimbert [4]. Studies also indicate that children aged between 3 and 5 years categorize people based on race and express racial bias. In a study, Cristol, \& Gimbert [4], observed that children understood how to categorize others based on gender and expressed bias such as isolating others with different racial affiliations during playtime.

\section{HOW RACIAL IDEOLOGIES ARE SHARED AMONG CHILDREN}

Conventionally, it was believed that children could not possess racial ideologies unless those ideologies were taught to them. However, research has disapproved that standpoint by determining that children can in their capacity develop racial ideologies. The studies further illustrate that the racial beliefs held by children are not exactly the same as those of their parents. According to Waxman [5], children naturally tend to learn and conform to the cultural norms under which they are brought up. This is a natural way to blend into the community and naturally adapt to the environment they are living in. Children naturally learn their environment, including various social norms that their parents perform. The children also collect a wide range of information even away from their families. The researchers have found out that the children have many sources of collecting the information outside their families, which they use to shape their beliefs. One of the famous examples provided by researchers regarding children's behaviour to learn outside their families is how they converse. If the kids learn entirely from their parents, the non-native kids would speak their parent's accents, but they do not. They learn to speak like natives largely because they learn so much from outside environments such as school.

It is important to understand the significance of knowing that children learn so much from their environment, but it is even more essential to understand why children develop racial biases early in life. It is an intriguing issue to contemplate because much as the kids learn from their environment, no one specifies the real meaning of the racial difference. Lam et al. [6] argue that such traits observed among the kids have both biological and cognitive as internal drivers and environmental \& societal factors as external drivers. Children who have not joined school have premature cognitive abilities, making them ripe for cognitive bias in racial stereotyping [6]. Even though such children can categorize people based on race, they cannot categorize people according to multiple dimensions. However, 
children are much more sensitive to even the slightest things they experience during their learning. For example, when a teacher says, "good morning boys and girls", the children have the ability to interpret that statement very deeply by recognizing that there is a major difference among the genders that is worth noting in the social interactions.

Children grow up noticing very slight things such as the height and hairstyles of people living in the neighborhoods. Therefore, children are likely to notice other kids or adults who have a different colour. The children naturally learn how to isolate kids who are different from them, especially in terms of colour. Waxman [5] noted that children tend to have a cognitive puzzle that makes them naturally judgmental about things they do not like. The children's brain can, on its own, develop judgment based on the little information that the child collects while playing with others or while learning or interacting with parents. Hence the children can create their meaning of race without adults having to explain it to them. Depending on where the children grow up, the racial ideologies are likely to take a permanent bearing at their tender ages. In America, for instance, a child is likely to grow up in mixed cultural settings in some parts of the country. Alternatively, a child can grow up in an environment where middleclass white culture appears to be the norm. Children raised in these environments will develop very distinct ideologies about racism. One will grow up with the mindset the middle-class white is the cultural standard in the country, and anything less than that is inferior.

In some parts of the United States where racism is prevalent, Kircher and Furby [7] observed that the books that kids read and the films on television contribute a lot in shaping children's racial ideologies. The books are often biased by portraying being white as the more acceptable state. As the kids interact with the books, they take note of the extensive use of white characters and white-related illustrations, which makes them naturally develop a negative attitude toward other races. They begin to notice that other races, such as black, are portrayed as weak and inferior to whites. Likewise, televisions programs tend to portray white people as more intelligent, creative and rich. Low conscious coverage and inclusion of other races in the television programs create an impression that the other races do not have the same superiority as the whites. Children also notice racial differences when interacting with the toys, and most of the toys have a bias in terms of race. The language and symbolist also magnify the whites, imprinting that the white people are superior to the kids.

Scientists have noted that even very young kids tend to portray in-group bias. Continuous observation has revealed that children might favour a group in which they are affiliated. The kids can quickly identify themselves to a specific group and attach certain standards to that group. Hence a child can label other groups as less critical. Children associated with weaker groups, such as black-American kids, also become aware of their vulnerabilities from as early as five years. The researchers thus believe that the parents of children of colour are much more likely to talk to their children about racism according to Renninger and Williams [8]. The parents teach their kids how to thrive in environments where there is racism or any other kind of racial inequality. The parents tend to insist on their personal pride of being affiliated with that group and ensuring that they create a positive self [8].

\section{THE IMPLICATION OF RACIAL IDEOLOGIES AMONG CHILDREN}

There is so much impact when children possess racial ideologies. As seen in various research findings, when the kids have such ideologies, their cognitive ability is not mature enough for them to regulate their response or how they treat other children. Children can isolate others or even say unpleasant things to other children they consider inferior in their innocence. Children who have racial ideologies almost invariably cannot hide their attitudes towards other children. Durrett and Davy [9] states that there is both physiological and psychological implication on children that are racially segregated and abused by other children. In many contexts of learning racism, it is considered that any kind of racist behaviour towards kids has longterm health implications on them. In particular, children suffer mentally, and they become limited from socializing freely with others. Their performance and general attitude towards studies are much affected by racist behaviours towards them. Children often develop fear or are affected by racial attitudes by simply observing and taking note of what is happening around them. For instance, kids will notice how their parents are being treated, and they will judge for themselves, after which their mental systems respond to that experience. In the worst-case scenario, children develop depression, anxiety and other behavioural problems even at their tender ages [9].

Children in minority groups can also have racial ideologies. Once children become conscious of being associated with a weaker ethnic or racial group, they become more defensive and negatively towards the races considered superior. Van Ausdale and Feagin [10] noticed that kids formed groups in schools based on their racial profile and in many cases, the children who belonged in the minority groups dissociated themselves from the natives during playing and other areas of socialization. The racial ideologies held by such minority groups kids tend to perceive the other race as unfair, and in some cases, children grow up believing that white people are naturally bad. Apart from being 
isolated and having many health and mental risks, children who consider themselves as of lesser race grow up being very sensitive and reactive to any negativity they get from other races. Van Ausdale and Feagin [10] explained that in a society like America's, racism is a continuous behaviour that is brought up from childhood and manifested in adulthood. Ideally, kids can easily learn and believe something, growing up with it until adulthood.

\section{INTERVENTION STRATEGIES}

The caregivers and the teachers remain mute about racial injustices and inequality because they think children are not supposed to hear them. Also, no one talks about racism in most cases because of limited information about racism and its history. Varies opinions and judgments about racism make it even more difficult to get to the bottom of the subject of racism. But the caregivers have so much to do regarding racist ideologies among children. It is appropriate to induce racial matters in children's conversations and neutralize those ideologies at tender ages. Such a conversation is inevitable since the children live in a society that racial inequality is rampant. Racism is very much prevalent in society, much as there have been drastic efforts in the past to address it. Specific recommendations have come to assist parents and teachers in addressing the issue of racial ideologies among children.

\subsection{Think about It}

Even though caregivers fail to talk about racism to children, it does not mean that they do not notice and carry racial ideologies. The caregivers need to engage in an open conversation with their kids who have these ideologies. It is natural for a child to react when they notice something unusual according to Murray and Alvarez [11]. Murray and Alvarez [11] provides an example of a white mother walking in the street with her child, and then they notice a black child wearing tattered clothes. The white child shouts to her mother seeking to know why the black child is dirty and ragged. The mother hushes her child and asks her not to talk about it. In this context, the writer advises that parents should not shun from discussing with their children in such a matter. It is essential for the white child to understand the reality as to why the black child has a different lifestyle. Otherwise, the racial ideology held by the white child is likely to grow and become a significant racial bias.

\subsection{Being Aware of Children Age}

Chang [12] found out that the parents often dilute the discussion about race because they feel that the children can be too young to hear certain things about race. The conversations' context is impartial and only focuses on the positive side of celebrating heroes and culture and leaving out racial inequalities. Various studies have proven that even tiny children notice racial differences and thus can have racial ideologies. Therefore, parents should consider discussing all the matters even with the smaller kids to ensure that those kids understand their environment sufficiently.

\subsection{Popularize and Take Seriously Racial Discussions with Children}

Parents tend to believe that children cannot be prejudiced, and so on many occasions, ignore instances where it appears like the children are being biased. Chang [12] discusses that issue, citing that ignoring such bias worsens the situation by causing it to grow. The caregivers must take notice of small instances where children react towards each other. They should notice the terminologies used by the kids and the contexts under which they are likely to discriminate against others racially. They should take the discussions with children seriously because if the habit of racially segregating others s not noticed and curbed in good time, the behaviour will likely grow with the child to adulthood.

\section{CONCLUSION}

The general idea about racial ideologies in children sparks a lot of debates in a different social context. Racial ideologies among children is not a very common thing as it is perceived to be non-existent. But several writers, through research, have determined that children in the tender ages can recognize gender boundaries and can, through continuous interaction with their environment, make racial categorization even without being taught. The children rely on their cognitive capacity to recognize racial differences and develop ideologies of their own to make judgments. Having a certain ideology regarding race has inevitable consequences for children. Their opinions and reactions are very much shaped by the racial ideologies they carry. For instance, kids from black families tend to be more defensive and easily overreact based on the racial ideologies they carry. It is crucial for the caregivers to take the conversations about racial identity with their children seriously. Ignoring such conversation is very problematic, especially in the context of addressing racism in society. Children will naturally learn and develop racial ideologies and do not necessarily need to be taught them. Hence, it is vital to involve them in an open conversation to help them learn and come to terms with what racism is all about.

Racial awareness among children is a complex but essential discussion in society. It was good noting that children develop racial ideologies from very tender ages as early as six months. Therefore, the entire discussion 
of racial identity should receive more focus in schools and at home. I feel it is essential to amplify the dissuasion of racism, especially among children, because addressing racism is often truly difficult when dealing with adults. Drastic efforts have been made in the past that involved massive movements, all seeking to address the growing racial segregation. But there has not been much attention on children. No one seems to have fully noticed that children grow up with bias they pick at very tender ages. The whole problem of racism cannot be fully addressed if it does not start with the children. The children carry racial ideologies to their adulthood. The children should be at the centre of discussions to help them understand the reality of the society of which they are part. It will help them change their standpoint of racism and probably begin to embrace diversity as part of the reality in society.

\section{REFERENCES}

[1] P. A. Katz, J. A. Kofkin, Race, gender, and young children. In S. S. Luthar \& J. A. Burack (Eds.), Developmental psychopathology: Perspectives on adjustment, risk, and disorder, 1997, pp. 51-74, New York, NY: Cambridge University Press.

[2] F. E. Aboud. A social-cognitive developmental theory of prejudice. Handbook of race, racism, and the developing child, 5571, 2008. DOI: https://doi.org/10.1002/9781118269930.ch4.

[3] E. N. Winkler, Children are not colorblind: How young children learn race. PACE: Practical Approaches for Continuing Education, 2009, 3(3), 1-8. DOI: https://doi.org/10.4324/97813152125174.

[4] D. Cristol, B. Gimbert, Racial perceptions of young children: A review of literature post1999. Early Childhood Education Journal, 2008,
36(2), 201-207. DOI:

https://doi.org/10.1007/s10643-008-0251-6.

[5] S. R. Waxman, Racial awareness and bias begin early: Developmental entry points, challenges, and a call to action. Perspectives on Psychological Science, 2021, 16(5), 893-902. DOI: https://doi.org/10.1177/17456916211026968 .

[6] V. Lam, S. Guerrero, N. Damree, I. Enesco, Young children's racial awareness and affect and their perceptions about mothers' racial affect in a multiracial context. British Journal of Developmental Psychology, 2011, 29(4), 842-864. DOI: https://doi.org/10.1348/2044-835x.002013.

[7] M. Kircher, L. Furby, Racial preferences in young children. Child Development, 1971, 2076-2078.

[8] C.A. Renninger, J.E. Williams, Black-white color connotations and racial awareness in preschool children. Perceptual and Motor Skills, 1966, 22(3), 771-785.

DOI: https://doi.org/10.2466/pms.1966.22.3.771 .

[9] M. E.Durrett, A. J. Davy, Racial awareness in young Mexican-American, Negro and Anglo children. Young Children, 1970, 16-24.

[10] D. Van Ausdale, J.R. Feagin, Using racial and ethnic concepts: The critical case of very young children. American Sociological Review, 1996, 779-793. DOI: https://doi.org/10.2307/2096453.

[11] I. E. Murray, A. Alvarez, Research to practice: New research on helping young children develop positive racial identities. Young Children, 2016, 16.

[12] S. Chang, Raising mixed race: Multiracial Asian children in a post-racial world. Routledge, 2015. 